\title{
Reporting on mental health difficulties, mental illness and suicide: Journalists' accounts of the challenges
}

202I, Vol. 22(I2) 303।-3047 (C) The Author(s) 2020

Article reuse guidelines: sagepub.com/journals-permissions DOI: I0.1 I77/|464884920903855 journals.sagepub.com/home/jou

\section{Anne O' Brien ${ }^{1 D}$}

Maynooth University, Ireland

\begin{abstract}
Media depictions of mental health difficulties and suicide are an important element in shaping how the public understands the issues and how relevant agencies devise strategies to advocate and reduce stigma. The role of the media in the production and reproduction of stereotypical portrayals of mental health difficulties and suicide has been of concern for a number of decades. However, relatively little research attention has been paid to date to the process through which stories on mental illness and suicide are produced by journalists. This article aims to contribute to that analysis by focusing on Irish journalists' experiences of and insights into the challenges underpinning reporting on mental health difficulties and suicide. Despite some generic and platform differences, journalists noted that their output was shaped by a number of factors, which included, sensitivity to the topic of suicide; care for families; balancing public and private interests; challenges to reporting facts, finding appropriate sources and meeting the needs of media platforms; interpreting guidelines on reporting and the discovery of the relative absence of mental illness stories. Understanding how journalists deal with these challenges can help them and advocacy agencies to address these challenges and thereby improve the nature of coverage of mental health difficulties and suicide in media output.
\end{abstract}

\section{Keywords}

Guidelines, mental health difficulties, mental illness, platforms, suicide

\section{Corresponding author:}

Anne O’ Brien, Department of Media Studies, Maynooth University, 0.24 lontas Building, Co. Kildare, W23F2H6 Maynooth, Ireland.

Email: anne.obrien@mu.ie 


\section{Introduction}

Media depictions of mental health difficulties and suicide are an important element in shaping how the public understands the issues and how relevant agencies devise strategies to advocate and reduce stigma for people with mental illness. The role of the media in the production and reproduction of stereotypical portrayals of both mental health difficulties and suicide has been a source of concern for advocates since the 1950s (Gerbner, 1959; Taylor, 1957). Media can tend to offer simplistic, inadequate and distorted representations of the extent and nature of the problems, which is stigmatizing (Coverdale et al., 2002). Media tend to emphasize dangerousness, criminality and unpredictability among people with mental health issues (Shain and Phillips, 1991; Signorielli, 1989). Entertainment and news media tend to offer overwhelmingly dramatic images of sever psychotic disorders (Day and Page, 1986). Similarly, with regard to suicide, the media has tended to report it in a way that depicts it as shocking and extraordinary, resulting from personal circumstances or clinical and medical reasons, rather than as a product of anomie resulting from profound social change (Cullen, 2006).

Some research has examined the broader media context in which stories on mental health difficulties are produced. Holland (2012) uses the concept of biocommunicability to model journalists not as mere transmitters of information but as the co-producers of medical subjects (2018: 1768). She examines Australian journalists roles in reporting, their news values, their sources and the challenges they face in reporting mental health issues. Holland (2012) finds that journalists conveyed a strong public service orientation to reporting on the subject (p. 1772). They sought case studies, problem areas of unmet needs, high-profile people, tragedy, controversy, new research and involvement from advocates to frame mental health issues as newsworthy (Holland, 2012: 1774). In terms of challenges to reporting, journalists were preoccupied by potential harm from language used and vulnerability of audiences (Holland, 2012: 1776). Subramanian (2014) engages with award winning journalists to determine that organizational and personal factors such as editorial support, professional experience, personal exposure to mental illness and empathy were factors that help them produce noteworthy stories. Respondents also proposed that positive coverage of mental illness was needed to redress negative coverage (Subramanian, 2014: 820). With regard to suicide reporting, Beam et al. (2018) note that journalists hesitate to report suicides but frequently do report on them. Beam et al. (2018) observes that in deciding to report, journalists go through a process of routinizing and rationalizing an exceptional situation in order to report it (p. 1447). Each of these studies offers potential concepts and concerns that can be addressed in the schedule of questions posed to participants. This article aims to contribute further to the body of knowledge in the literature by arguing first, that mental illness is still a topic largely omitted from media discourse because journalists do not believe that they have the expertise to cover the issue. Second, this article notes that media production requirements have changed considerably in the last 10 years. Therefore, understandings of journalists' approaches to topics like suicide and mental ill health, which are based primarily on data on print journalism, are no longer exhaustive. This article updates that understanding by noting that journalists claim that new media functions such as rapidity of turnaround, constancy of updates, search-ability, digital replicability, the advent of 
commentary and the perpetual nature of digital output are re-shaping journalists thinking on their reporting practices. The digital affordances of journalism and how they impact on sensitive reporting still requires further study. Third, this article finds that while journalists are respectful of guidelines, they are more interested in the availability of ongoing guidance from expert bodies, who may need to be more proactive and engaged to respond to journalists in the future. In addition, this research is conducted in the Irish context, which had not previously been explored with regard to reporting on suicide and mental ill health.

\section{Research methodology}

While the case study methodology clearly carries with it documented contingencies of working from a small sample in terms of limits on the explanatory range (Yin, 2014); nonetheless, well-chosen case studies can provide opportunities to produce important exemplars, generate practical, context-dependent knowledge and have merit in their proximity to studied realities (Flyvbjerg, 2006). As such, findings outlined below are not offered as a comprehensive model of the complex factors that shape all media production. A large body of research has been directed at modelling how news is produced but this article does not problematize processes of news production per se. Rather, it builds on work that accepts that news values, work routines, resource allocation, imagined audiences all play a role in determining what makes the news and how it is reported (Briggs and Hallin, 2016). Instead, this research offers an inductive study of the specific experiences and understandings of a group of Irish practitioners as they navigate the explicit and implicit procedures that shape reporting on mental health difficulties, mental illness and suicide, within their pre-existing working models or practices of news production.

Data were derived from semi-structured interviews with a purposive, snowball sample of 18 key media professionals from radio, television, print and online outlets. The first journalist in the sample was personally known to the author and each respondent suggested other candidates. None of the journalists were specialists in mental health reporting, rather, they were news or features reporters who on occasion covered these topics as part of a more general brief. All interviews were conducted by the author, some in person and some over the phone, most lasted approximately 1 hour. The breakdown of platform and roles pertaining to each contributor is described in the Table 1 below.

Table I. Table of participants.

\begin{tabular}{llll}
\hline Radio & Television & Print & Online \\
\hline Editor (I) & Executive producer (I) & Journalist (2) & Editor (I) \\
Producer (I) & News editor (I) & & Journalist (2) \\
Reporter (2) & Producer (4) & & \\
& News reporter (I) & \\
& News journalist (I) & \\
& Camera operator (I) & \\
& & & \\
\hline
\end{tabular}


Respondents were asked a series of questions from an interview schedule about how stories typically come to their attention and what constraints on sources or time shaped their approach. Questions were asked about how journalists used language to name events in a story and how they captured the complexity of situations in their output. How much editors, guidelines, deadline pressures and working relationship with suicide prevention organizations either helped or hindered journalists was also explored in a number of questions. All interviews were audio recorded, transcribed and anonymized. Confidentiality was assured, with any details that might reveal the identities of participants changed, this included changing gendered pronouns for some respondents and omitting programme titles and on occasion descriptions of programme content. Transcripts were coded, by the author, for recurrent concepts or ideas that were repeated across respondents' answers. For instance, the codes of risk, concern, care, stigma were recurrent because many journalists used those terms to explain the challenges to reporting. Additional codes that were derived from the literature reviewed were searched for in the transcripts. For instance, 'contagion' was a concept from the literature that the author searched for in interviews. Codes were clustered together to generate themes and those themes were analysed to generate an overarching framework for examining journalists' experiences, which was structured around the key challenges journalists named. These are described in detail below in the 'Findings' section.

There were very few discrepancies in the responses of the journalists but some variations in the challenges respondents experienced can be accounted for by the genre of output that they worked in, whether this was news and current affairs production or whether they worked in features or documentary programming. Many news reporters spoke in particular about covering murder-suicides whereas features producers spoke more to the topics of mental illness and mental health difficulties, as well as suicide. There was also some variation across platforms, that is, between radio, print, television and online, but perhaps surprisingly, these were not as significant as the differences accounted for by generic conventions and requirements. Features producers were more likely to cover individual suicide stories and mental health difficulties, whereas news journalists were more concerned with coverage of critical incidents. Finally, recommendations were sought on how challenges might be better addressed. The findings outlined below analyse what journalists said in response to the line of questions, which was in turn informed by the key themes that arise in the academic literature on reporting suicide and mental illness.

\section{Findings}

Despite various generic differences between news and features production, journalists' output was shaped by a number of key factors identified as themes in the data by the author because they were common to many of the respondents. These factors included, a sensitivity to the topic of suicide; concern for grieving families; attempting to balance public interest and privacy; challenges to accessing the facts of a story, finding appropriate sources to comment and meeting the needs of various media platforms; interpreting guidelines on reporting fairly and noting the relative absence of mental illness stories. 


\section{Sensitivity to the topic of suicide}

Journalists were Cognizant that suicide was a sensitive topic and they claimed that they did approach the issue carefully. Sometimes, journalists' sensitivity involved not reporting a death. As Beam et al. (2018) note,

Determining whether to cover a death by suicide can be a high stakes decision for journalists ... to merit coverage, a suicide must intrude into the public arena, must affect a community, must be unusual, or must be a vehicle for drawing attention to a larger social problem. (p. 14)

As one radio reporter concurred, 'A typical ordinary suicide we wouldn't cover . . . Because a suicide of itself is just like a natural death you just wouldn't report on it' (Radio Reporter 3). Journalists were clear that the motivation for being sensitive also centred on avoiding stigmatization of suicide deaths. As an online journalist put it, 'Any media organisation that I've ever worked for strictly avoided using the phrase "committed suicide" so as not to stigmatise suicide' (Online 1). A television news editor agreed, 'Where does the caution come from, defamation, getting it wrong, your own reputation? No. I just think it's the sensitivity to the people involved, the case itself' (TV News Editor 1). In addition, there was a strong acknowledgement of social responsibility from a number of respondents that contagion, a process by which one suicide becomes a compelling model for successive suicides (Gould and Davidson, 1988) could be an issue if suicide reporting was detailed as regards the method. 'Contagion is the biggest challenge, you don't want to be giving people ideas, so you don't want to mention here's how someone did it' (Online 2). In sum, journalists avoided reporting suicide unless there was an exceptional public interest reason to do so, where that was the case they tried to be cognizant of balancing interest from the public arena with care for individuals affected.

\section{Care for families}

Journalists were empathic about the position of families and loved ones of suicide victims or mental illness sufferers. Much as Holland (2018) found with regard to reporting on mental health difficulties (p. 11), journalists were concerned about putting such people at risk, but the Irish journalists were also conscious that telling stories might be problematic for families. As a producer put it,

There were many stories that we would have liked to tell but we couldn't because it was either the families themselves didn't think it was suitable for their stories to be featured, or they were fearful of a backlash from the services . . . (or) by putting them up on screen that might in some ways make it worse for them. (TV Producer 4)

In that case, the producers did not tell the stories. A producer on a mental illness documentary added that sometimes families were willing to talk but potential participants were not. 'We were interested initially in talking to families as well, that was really difficult because while the family might have spoken they needed the permission of their loved one and in many cases, they weren’t willing to speak' (TV Producer 3). 
Another situation with families was that the decision to participate in a programme about mental illness could cause conflict for the participant. As a producer explained,

What I find a lot, is people themselves who take part in our programmes have issues with their own families, there are divisions, and disagreements about taking part in media . . . they have to deal with that and then I have to deal with them . . . (TV Producer 3)

Similarly, with suicide reporting there was a dilemma for journalists to address between reporting the fact of a death as a suicide and choosing to protect the privacy of a family. As an online editor put it,

There would be an understanding that it's a very sensitive thing for a family, a tough thing to deal with. So, I think that the tone and language that we use would be very different to what we would use with, for instance, a gangland shooting . . . there is more consideration given and people are more thoughtful. (Online Editor 1)

This dilemma manifested in terms of the language journalists felt they should use to describe the death. Some frustration was expressed with the use of euphemisms such as 'died suddenly' or 'died tragically' to describe deaths that were suicides and which were impacting on a community. There was a sense that the obfuscation potentially added to stigma around the nature of the death. As one journalist explained,

When we were covering the case of (a woman's) funeral . . I noticed that other papers spoke of her 'dying tragically', 'dying suddenly', 'dying in tragic circumstances' and I talked to the editor . . . and he said I think we should say straight out that she took her own life. And it was so much part of the narrative at the funeral . . . the family were very clear and quite open about it, I think maybe we should say it was a suicide instead of all of this kind of 'died suddenly'. There's no shame in it, when that's the story, that's what it's about. (Print 1)

Journalists were again influenced by the position a family took regarding the death. While the obfuscating terminology noted earlier is still used in some situations to flag a 'sudden and tragic' death, when families were leading by using clarity in how they defined deaths then this encouraged journalists to follow that lead. This finding adds further validity to Skehan et al. (2006) who find that those bereaved by suicide might want more reporting of suicide if it is done sensitively and with supports for those impacted to navigate their relationship with the media. In short, the personal experience of families of people with mental health difficulties, mental illness or those bereaved by suicide shaped decisions that journalists made about how to report and frame the story.

\section{Balancing public and private}

Different types of suicides led to different approaches to getting a fair balance between protecting private family grief and serving the public interest. As a journalist explained,

Let's say there's a suicide in a school, people will walk on eggshells and treat it really sensitively and it may not even be reported. But with a murder suicide you'd treat it more like 
a murder, where a crime has been committed, so there's an argument that those rules should apply. (Print 2)

An online editor was clear that the idea of public interest was not a valid rationale for naming the death of a particular celebrity as suicide:

She passed away and there would have been legacy issues with mental health for her. You have a woman who has 100 s of millions of followers ... and people want to know what was the cause of her death . . . and it's a tricky balance between the public and private. What do the public need to know? Do they need to know how she died? Maybe they don't and that's a challenge, to protect privacy. (Online Editor 1)

A television producer noted there was also a balance to be struck between getting the strongest story to tell the public and a duty of care to the privacy of contributors. She commented,

Throughout we make sure that the people we choose . . . have a very defined reason why they want to (tell their story), so that we're not just pulling them along, without being straight with them, or in any way trying to feature people that are in a precarious position in terms of their own mental health. (TV Producer 4)

Balancing public and private interest was also framed in terms of journalists performing a duty to their audience. As one television producer noted, 'I think that we have a middle of the road audience, for our news and we don't sensationalise or scandalise' (TV Producer 2). A print journalist similarly observed,

The next day there's not going to be an inquisition into why we didn't have the detail that the other titles or tabloids had because there's an expectation that other outlets will go further, but we are choosing not to go beyond a point . . . so that readers trust you more. (Print 2)

An online journalist noted that the audiences input also shaped their approach 'We get emails (from readers) about stories we are covering. So, for us, it's a real challenge to make sure that we listen to what the readers are saying' (Online 1). As one producer noted regarding the Irish audience generally 'I think Ireland is a small society and you're not too far away from any particular individual and that brings a greater sense of responsibility' (TV Exec Producer 1).

While respondents were clear that they approached mental health difficulty and suicide stories sensitively, attempting to consider the families position and to carefully balance public and private interests, these were not very straight-forward decisions, and were very context-dependent. In short one of the main challenges journalists faced was that there were no hard and fast 'rules' that could be simply agreed and followed when it came to sensitivity, considering family and balance, each depended somewhat on the context and impact of the story. In addition, journalists faced numerous other news-gathering and practical challenges in covering the topics appropriately, such as finding the facts of a story and appropriate sources to tell the story. 


\section{Facts of the case}

As noted earlier, when asked generally about covering mental health difficulties or suicide, news reporters often spoke specifically about covering murder-suicides, while features and documentary producers spoke more to the topics of mental illness and mental health, as well as suicide as a social problem, rather than as a critical incident. Each of these two approaches, news and features, are described separately below. A primary concern for news reporters working on a (murder) suicide story was on limiting all discussion to verifiable facts about the story, however accessing accurate facts was not unproblematic. As an editor said, 'In general . . . from a news point of view we have to cover all mental health (difficulty) and suicide stories factually, we can't allow commentary to seep in . . . we just have to tell the facts as they are' (TV News Editor 1). This meant that news reporters were reliant on a limited number of potential sources to give them the facts of the story, particularly for a breaking news story. The main source for factual information at a murder-suicide was The Gardaí, who were problematic because they were highly reluctant to engage with journalists. Many respondents felt that 'they're very cautious, too cautious sometimes' (Radio Reporter 2). Another respondent put it more strongly 'The Garda press office are terrible . . . they're not getting the information from the scenes back to the press office. So that's kind of an obstacle' (Online 1). Another editor explained further,

They're so reluctant in case they ... say something wrong and they don't have the media training to be able to deal with the media briefing, or to be able to deal with being asked difficult questions. But they just seem to shut down on any sort of comment . . . even if they said 'We're not looking for anyone else in relation to this' at least then you can leave it up to the viewer to infer that the crime was committed by someone within the house who then took their own life ... (TV News Editor 1)

Because the police were slow to offer specific and clear facts and information about individual cases of murder-suicide, journalists then proceeded to talk to bystanders, who could add little by way of fact or understanding or overarching context to the story.

\section{Problematic news sources}

As one reporter explained, regarding reporting on murder-suicides,

When you land at a scene like that you talk to neighbours, you would usually talk to people in the local GAA (sports) club ... In that situation you would usually talk to the parish priest (church leader), you would talk to local Councilors (politicians) . . . It's kind of doing a broad sweep of as many people as possible because the more you talk to the more information you get. (TV Reporter 1)

This 'broad sweep' in itself created a norm of depicting grief and the emotional responses of the community, 'You go to the scene and cover the initial trauma and shock in the community' (TV News Editor 1), which means that stories are presented as emotional and inexplicable isolated incidents rather than part of a larger social problem and 
pattern. By approaching these sources little opening was left for any alternative sources, such as experts in suicideology, who might offer greater context to these incidents. Journalists expressed an ambivalence about the usefulness of experts or data as sources for their reporting, which they sensed an audience might not relate to so easily. As one reporter put it, 'You need the context as well but without it being too statistic heavy because people don't understand that' (Radio Reporter 1). In sum, despite wanting to be sensitive to the topic, oftentimes the practical challenge of finding sources for commentary left journalists mapping a general public response rather than offering a depth of context to frame the story within broader patterns in society.

\section{Features production}

Beyond the immediacy of news production, feature and documentary writers and producers could dedicate more time and resources to their coverage of suicide and mental health difficulties than news, but this, they believed, brought an additional responsibility to cover the issues well. As one producer put it,

When you come to (suicide) as a producer on a big documentary you know you won't be coming to it again in the next year . . . so there's a bigger responsibility on our shoulders to make sure that we use the time well to say something relevant and of benefit to the subject itself. (TV Producer 4)

As Subramanian (2014) and Henson et al. (2009) found, journalists understood that 'involving people with mental illness as sources in news stories is a way to reduce stigma and portray people with the illness more positively' (Subramanian, 2014: 14). Much as Holland (2018: 12) found, sources were not difficult to find for mental health stories in features departments. A television producer noted, 'It's very easy to find the case studies to come on air . . . there are literally so many people . . . It's horrific that there are so many people you can talk to . . ' ' (TV Producer 2). In contrast to Holland's findings regarding Australia, there was no evidence in the Irish case that journalists felt suspicious of participants' motives.

Although journalists did not struggle to find sources for suicide or mental health difficulty features they were very clear that nonetheless a lot of challenging work went into engaging with sources in order to craft these types of in-depth stories. Very experienced workers used expertise and effort to ensure that the topics were covered well:

Producers and researchers ... approach it in a certain way and they work hard and work through the agencies, who can often be very helpful, because you can't knock on the door and ask people about suicide in their families. There are time-consuming steps to eventually get there and people do eventually get there. (TV Exec Producer 1)

This challenging engagement with sources was equally the case for covering mental illness. As a television producer explained, 'I'm in the game a long time with a lot of experience so there was a lot of trust there' (TV Producer 3). In addition to building a relationship of trust with the participants, producers on mental illness programming had to sometimes work to reassure broadcasters who, 
Were very nervous and cautious around the whole thing. They had this idea that we would get the person's psychiatrist to sign off that this person was capable of understanding the process and doing an interview, (but) you wouldn't be asking a consenting adult who wasn't suffering from any mental health issue to get their doctor to sign off. . . In the end they got that point when I explained it but that gives you an idea of what you're dealing with initially. (TV Producer 3)

Much as Subramanian (2014: 9) notes across all platforms, respondents were cognizant of the need to build a relationship with potential participants to get the content, but at the same time they were concerned with their duty of care. Producers in live television sometimes had relatively fleeting engagements with participants but nonetheless they made a point of acknowledging contributors. 'I always make a point of going out (from the control room) to say thank you for coming in, we've a manic show but if someone has put their heart and soul out I always want to acknowledge that' (TV Producer 2). Radio producers were clear that they emphasized collaborating with participants and being mindful of their limits around discussing suicide and mental health 'for an interview we'll talk about areas that they don't want to get into or can't get into' (Radio Editor 1). However, the work that went into building trust and care in relationships with contributors had to be balanced with retaining control over the editorial content and direction of the programme.

This was a very tricky balance for journalists to maintain. As a documentary producer explained,

I would give (contributors) an early viewing but they can't be in the edit suite, they can't have any part of the editorial process, and there's good reason for that, because they're emotionally involved and they're not necessarily the best person to tell the whole story . . . (TV Producer 1)

Despite all of the diligent effort brought to bear in a production, journalists were aware that viewers might ultimately switch off if the programme was too intense or too difficult to watch. As a documentary maker put it 'you're not just doing a series of interviews with people who are terribly sad, because it's hard to watch, just uniformly melancholy' (TV Producer 1). Producers in television were mindful of how easy it was to switch off, 'We are competing with entertainment shows so we do have an onus not only to cover the subjects but to get people to watch them. If your ratings are terrible it doesn't bode well . . .' (TV Exec Producer 1). That journalist responded to the challenge of making material watchable by highlighting some potential solutions to mental health difficulties and suicide problems in her programmes. As she put it, 'it doesn't all have to be bleak ... and that's a conversation in general for journalism, to show that there's a problem but to also maybe show that there's another way of handling this . .' (TV Exec Producer 1). As another television producer put it, 'we need what we would call an uplift, an inspiring event, people are inspired by people who are trying to move on to help others' (TV Producer 1). Beyond trying to first, manage contributors to tell their stories while maintaining a duty of care, second, retain editorial control over content and third, keeping the public engaged with difficult subject matter, as described earlier, there were other additional challenges that were unique to the various platforms for which journalists worked. 


\section{Platform specific challenges}

Regardless of outlet, journalists noted that the main pressure on them in relating a story came from the rapidity of turnaround, which has increased in the last decade as a result of the networked and instantaneous nature of social media, its ubiquity and its 24/7 content cycle. As an online editor explained,

The pressure is to get information out and as quickly as you can. You're still trying to double and triple check everything you can, but realistically, if you have 7 or 8 websites and they're all pushing to be first then . . . of course people will make mistakes. I don't think the problem is sensationalism, it's the speed with social media and a few people all confirming they heard the same thing but that doesn't mean that it's true. (Online Editor 1)

An additional issue that online outlets had to address in balancing public interest with protecting story subjects was the role that commentary now plays for media audiences. As an online journalist explained, 'The way we operate here is that comments that are distasteful would be brought to our attention when they're flagged but we wouldn't moderate or check content . . . there is no policy on closing comments for suicide stories' (Online 2). As a result, online outlets felt that they 'get criticized a lot more than other places would because of the comments' (Online 1).

In addition to dealing with commentary as a dimension of their production, online journalists also had a clear sense that their material was digitally searchable, replicable and existed in perpetuity, which was another subtle pressure on them when covering sensitive topics for news. As one journalist related,

An aspect of working on line is that it's there forever if someone does a report on suicide or mental health or anything else for that matter, it's not like the newspaper, where it gets published the day before and if that paper is circulating or in a person's possession a year later that's incredible. But now people go online and google and see your suicide reports and it's there for them to see ... (Online 2)

In addition, digital journalism facilitates constant updating, as one respondent described 'We'd see ourselves increasingly as a broadcaster, that you're updating online constantly' consequently 'when stuff is breaking online, you're making those decisions' on how much detail to include in a story much more frequently, under time pressures

and that does elevate it and put pressure on the decisions . . . That's where experienced heads are important, editors who ... know there's a point to which you go and no further and have the confidence to make a call. (Print 2)

As well as relying on experience to determine many of these pressure-based issues, journalists were also cognizant of the existence of guidelines to assist them in reporting on mental health and suicide but were keen to avail of more guidance on best practice from relevant advocacy agencies, particularly in the immediacy of a critical incident. 


\section{Guidelines}

Holland (2012) notes that deploying guidelines too prescriptively may work to threaten rather than cultivate relations with media professionals. While all respondents were aware of the existence of guidelines, some respondents admitted that they did not necessarily have them to hand, nor did they consult them frequently. 'I'd hope I'm aware of them but I don't think I've looked at them in a long time. I know the NUJ issued some maybe 10 years ago or more ...' (Print 1). Although some journalists had a rather generalized sense of the existence of guidelines, others were very clear that they did use guidelines and frequently consulted them. In television production, there was awareness that 'Guidelines are important . . . and we've always abided by the guidelines ... they were always distributed to us in news ...' (TV Producer 2). Another executive television producer agreed, 'guidelines, while they do sit in the background, they do inform people' (TV Exec producer 1). In online journalism, there was a positive reception to guidelines 'I think the guidelines are quite good, so that people are treated properly and that it's reported fairly' (Online Editor 1). An online editor concurred, 'Yeah we look at the guidelines around once a month or every six weeks just for a refresher' (Online Editor 1). And also in the context of radio production there was a sense that 'The media guidelines that have been put out over the last number of years, journalists are generally more aware of them so that has helped improve coverage' (Radio Editor 1). The proactive dissemination of guidelines by advocacy agencies in Ireland, might help to explain why this finding contradicts Collings and Kemp's (2010) study in New Zealand, which found that few journalists were aware of guidelines and reported not using them. It also contradicts Beam et al. (2018: 14) whose US study showed journalists were slow to relinquish the journalistic norm of 'full disclosure' and breached guidelines in describing method and location, this was not generally the case among Irish journalists.

Whether they used them frequently or infrequently, the main thrust of respondents' understanding of the guidelines was consistent. This was that they should be careful in how they named suicide, they should not include details on suicide method, that there was a risk of contagion and that they should include references to helplines. As a print journalist said, 'We would always put at the end of a piece "If you've been affected by this talk to Pieta House or the Samaritans"' (Print 1). One radio reporter spoke to the ubiquity of helplines in terms of covering suicide and other stories:

The Samaritans, I mean it is a bit clichéd, but it's rolled out for everything. Sometimes I do kind of think, oh god, the poor Samaritans, they have to deal with everyone. People including the Gardaí and journalists seem to use it as a get-out clause, but it is seen as the responsible thing to do, to offer some way or direction towards whatever help you might need. (Radio Reporter 2)

Another journalist observed that a benefit from the convergence towards online publication was an increased practice of referencing support lines in online content. As he put it, 
We were told by editors to mention support numbers and that, but in the print version of newspapers there wasn't that kind of approach to support numbers . . so that's something that has changed over the form of delivery, the online is more tuned in. (Online 2)

When discussing guidelines, respondents engaged in a further consideration of one of the key challenges they faced in complying with guidelines, which was their use of language within their productions. As a radio producer noted, 'If we're booking an item in this area, we would discuss it and direct people to a couple of handy quick guidelines that are available as to the language to use' (Radio Editor 1). With regard to breaking news stories of murdersuicide, journalists were led by the language that sources used. As one editor described,

We would always try to attribute language, so if a family member comes out and says this is a 'tragedy' and such a such was being treated for depression or other mental health illnesses . . . then we feel perfectly comfortable saying that and using that. (TV News Editor 1)

There was less discussion from respondents about the appropriate language to use when discussing mental health difficulties and less sense of a clear cut 'rule' about language, the dos and don'ts of mental health difficulties or illness reporting relative to the clarity around suicide reporting. Interestingly, one journalist pointed to a possible generation gap in understandings of the importance of sensitivity in reporting on mental health difficulties and suicide. As he put it,

Younger journalists tend to be a bit more aware of how to approach things but people who might be covering mental health issues for years might not realise that there are certain things that you should not say or do on air. I think there can be a gap there. It can be an issue if colleagues aren't aware that you can't talk about a suicide note for instance, there can be a gap there. (Radio Editor 1)

Some other observations on guidelines were that they were difficult to apply to the specifics of a particular story and that a point of contact for ongoing, active engagement from within an expert organization would be useful. One producer commented in the case of a 'murder-suicide, we were issued with guidelines as to how to talk about it. But they're too generic. Like it would help to call someone and get more guidance on the specifics' (TV Reporter 1). Increased, ongoing and more frequent engagement with experts in suicide and mental health advocacy organizations was something about which journalists were receptive. In terms of print, one journalist commented, 'More proactive contact from NGOS on guidelines yeah, I'd be open to that, it would be no harm' (Print 1). Journalists valued the provision of copies of guidelines 'It would be worth having them stuck up in every newsroom and if they were on a card, like something you could have in your wallet, that you could look at them again, that would be great' (Radio Reporter 3). An online journalist agreed, 'We would always be open to agencies approaching us, it's a big issue and it's only going to become bigger . . . it's great that now people will say "Oh here's an idea for a story" that's great' (Online 2). While attitudes to guidelines and engagement with agencies were positive, much of this discussion was framed in terms of the topics of suicide and mental health difficulties. Throughout the research, mental illness was not raised as much as a focus for discussion by journalists. 


\section{The relative absence of mental illness stories}

In most of the responses to questions about mental health difficulties and suicide the respondents focused either on dramatic murder-suicides or common mental health challenges. This finding is very much in line with Holland (2018: 10) who also found that some mental health conditions received less attention than others. In many ways, mental illness was framed out of the discussion with Irish journalists and so constitutes a 'missing piece' around the challenges that journalists face in covering mental illness. Schizophrenia, psychosis and other mental disorders did not achieve the same level of recognition among producers or journalists as important topics that required coverage. This also corroborates an analysis of reports to the StigmaWatch programme in Australia, which found that schizophrenia is often represented in an inaccurate, sensationalized way, promoting an association with violence, while depression is far more likely to be reported responsibly and positively, with other conditions receiving little coverage (StigmaWatch, 2013: 10). A key challenge that journalists admitted they faced with regard to this type of reporting was a limited understanding of mental illness. Understanding the complexities of mental illness, maintaining an awareness of information relevant to the story, the emotional nature of the subject matter and the stigma attached to it, all made mental illness harder to cover. As one journalist put it,

I think there's still a bit of stigma, people don't understand it, people are still slightly scared about it. And it's probably the next step, to lift the veil around some of this. Even explaining these conditions and how they affect people is difficult. (Print 2)

In a similar vein, there was an additional bias in coverage of mental illness, whereby in many cases it was only the success stories that were told, while ongoing struggle receives less coverage. As one journalist said,

You are kind of perpetrating the stereotype by only interviewing the person who's way further down the line and has come through the other side. And it's - if I can do it he can do it - but that's not the reality. If you're always speaking to the person who did get better, you know, there are people who can't even imagine getting to that point. So, there is certainly a spin on that, there's a 'positivity' to it. (TV Journalist 1)

This situation occurs perhaps because of the difficulties of 'capturing' ongoing illness in a neat way for media content and perhaps also because of very genuine concerns for vulnerable adults receiving media exposure while still in the process of addressing their illness.

Despite the challenges posed by covering the topic of mental illness, there was some expression of willingness to consider undertaking more and better coverage. As one journalist said,

We probably should be covering more about people with a severe mental illness in a way that doesn't impinge on their privacy, or demonize them, so you can see the person in the middle of the illness . . . All we hear is about hospitals, or prisons, or mothers being attacked by sons, and they're people who are sick . . It would be good if we heard a bit more about it. (Print 1) 
One producer who had successfully made a documentary about mental illness summarized the challenge in terms of the stigma that participants face:

It's hard to cover because there's so much fear out there. The stigma is massive, that's what everybody who didn't want to talk, talked about. Wanting to hide it, most people can't hide it, but it's very personal, it's very private. People come to it with misunderstanding and stigma but the upside of that is that there is a fascination that people will watch it . . (TV Producer 3)

Clearly there was support among journalists for sensitive and improved coverage of mental health difficulties and suicide.

\section{Conclusion}

This research has provided an analysis of the processes through which journalists and producers of news and factual programmes produce messages related to mental health difficulties and suicide as topics. This study echoes some of Holland's (2018) findings about the challenges journalists face in reporting on mental health difficulties. Preoccupation with causing harm was subtly different in the Irish context however. Irish journalists were not explicitly concerned with avoiding harm but instead framed their approach in terms of care and concern for participants and their families. Empathy and a desire to serve the public by highlighting mental health difficulties and suicide as social problems were common to this and Holland's study on Australia. In contrast to Subramanian's (2014) study, Irish journalists did not only state that more positive stories were needed about mental illness, but also noted the dearth of coverage of the topic. Beams description of processes of routinization shaping journalists' decisions to report suicide stories is also reflected in the Irish case but the latter underlines the importance of context and individual cases to shaping that decision.

What all of these studies have formed together is an iteration of the importance of understanding how and why journalists report on suicide and mental illness in the ways that they do so that such reporting can be improved and work towards best practice. What we know from this body of research is that journalists are careful with the topics of suicide and mental illness, that they struggle to balance public and private interests, that reporting is impacted by the sources of information available, that family reactions to reporting are taken into consideration and that sources and language can be a challenge to effectively shaping content. What this study adds to this generalized knowledge of journalism practices and suicide or mental illness reporting is that it is also important to consider media forms as central to the project of understanding how media narratives are formed. Radio and television producers have corroborated many of the findings derived from print workers. In addition, however, journalists working in the contemporary ecology of online media platforms have new concerns centred on the rapidity of turnaround, the constancy of updating, the advent of user-commentary on content and the ubiquity, search-ability, replicability of content that is now availability in perpetuity, all of which are dimensions of an 'always on' digital news culture. As well as questions of media form, the study also challenges presumptions about journalists ontology. Journalists are assumed to resist interventions by expert bodies that wish to curtail their freedom of 
expression but this study notes conversely that journalists welcome not just guidelines but ongoing and engaged guidance from organizations to better shape their understanding. A key gap in that understanding, revealed in this study, highlights the lacuna in mental illness reporting whereby many journalists felt ill-equipped to report on conditions that they did not understand. This finding opens the possibility for greater collaboration between researchers, expert bodies and journalism organizations and networks to better equip journalists for greater and ongoing engagement for the improvement of future reporting on mental health difficulties, mental illness and suicide.

\section{Acknowledgements}

The author would like to thank the journalists who gave so generously of their time to assist this research. In addition, she would also like to thank Headline for their generous support and the anonymous reviewers for their helpful comments.

\section{Funding}

The author(s) disclosed receipt of the following financial support for the research, authorship, and/ or publication of this article: This article is based on a research report funded and supported by Headline, Ireland's national programme for responsible reporting and representation of mental illness and suicide.

\section{ORCID iD}

Anne O’ Brien (iD https://orcid.org/0000-0003-2306-1415

\section{References}

Beam RA, Lockett John S and Mead Yaqub M (2018) We don't cover suicide . . . (Except when we do cover suicide). Journalism Studies 19(10): 1447-1465.

Briggs CL and Hallin DC (2016) Making Health Public: How News Coverage Is Remaking Media, Medicine and Contemporary Life. Abindgon; Oxford: Routledge.

Collings SC and Kemp CG (2010) Death knocks, professional practice, and the public good: The media experience of suicide reporting in New Zealand. Social Science \& Medicine 71(2): 244-248.

Coverdale J, Nairn R and Claasen D (2002) Depictions of mental illness in print media: A prospective national sample. Australian and New Zealand Journal of Psychiatry 36: 697-700.

Cullen J (2006) Meanings, Messages + Myths: The Coverage and Treatment of Suicide in the Irish Print Media. Dublin: Health Service Executive.

Day DM and Page S (1986) Portrayal of mental illness in Canadian newspapers. Canadian Journal of Psychiatry 31(9): 813-817.

Flyvbjerg B (2006) Five misunderstandings about case-study research. Qualitative Inquiry 12(2): $219-245$.

Gerbner G (1959) Mental illness on television: A study of censorship. Journal of Broadcasting 3: 293-303.

Gould MS and Davidson L (1988) Suicide contagion among adolescents. In: Stiffman AR and Feldman RA (eds) Advances in Adolescent Mental Health. Greenwich, CT: JAI Press, pp. 29-59.

Henson C, Chapman S, McLeod L, et al. (2009) More us than them: Positive depictions of mental illness on Australian television news. Australian and New Zealand Journal of Psychiatry 43(6): 554-560. 
Holland K (2012) The unintended consequences of campaigns designed to challenge stigmatising representations of mental illness in the media. Social Semiotics 22(3): 217-236.

Holland K (2018) Making mental health news. Journalism Studies 19(12): 1767-1785.

Shain RE and Phillips J (1991) The stigma of mental illness: Labeling and stereotyping in the news. In: Wilkins L and Patterson P (eds) Risky Business: Communicating Issues of Science, Risk and Public Policy. New York: Greenwood Press, pp. 61-74.

Signorielli N (1989) The stigma of mental illness on television. Journal of Broadcasting and Electronic Media 33(3): 325-331.

Skehan J, Greenhalgh S, Hazell T, et al. (2006) Reach, awareness and uptake of media guidelines for reporting suicide and mental illness: An Australian perspective. International Journal of Mental Health Promotion 8(4): 29-35.

StigmaWatch (2013) Tackling Stigma against Mental Illness and Suicide in the Australian Media (Report). Melbourne, VIC, Australia: SANE Australia.

Subramanian R (2014) Covering mental illness: Challenges and solutions. Journalism Practice 8(6): 809-825.

Taylor WL (1957) Gauging the mental health content of the mass media. Journalism Quarterly 34: 191-201.

Yin RK (2014) Case Study Research Design and Methods, 5th edn. Thousand Oaks, CA: SAGE.

\section{Author biography}

Anne O' Brien is a Lecturer with the Department of Media Studies at Maynooth University. She has published a number of articles on the representation of women in radio and television, on women workers in creative industries and examined why women leave careers in screen production. She has also undertaken research on community media, examining its social benefit and governance needs in funded projects for the Broadcasting Authority of Ireland. Her book, The Politics of Tourism Development, Booms and Busts in Ireland (Palgrave Macmillan, 2011) examines the role of the state in the development of Irish tourism. Her most recent book explores Women, Inequality and Media Work (Routledge, 2019). 